\title{
Fasting may be an alternative treatment method recommended by physicians
}

\author{
Ferah Armutcu ${ }^{1}$
}

\begin{abstract}
Objective: Fasting is a practice found in many cultures both ancient and modern. Although, fasting (religious or otherwise) causes many physiological, biochemical, metabolic and spiritual changes in the body, there is no clear scientific consensus on its beneficial effects on health. Also, despite the popularity and potential promise of therapeutic fasting as a preventive measure, little is known about the prevalence of therapeutic fasting use. This study was performed to discuss whether could fasting be part of wellness?

Method: It is reviewed lately conducted studies in regarding the impact of fasting or Ramadan fasting on health. It was searched, MEDLINE/PubMed and Google Scholar databases by using 'Fasting', 'Ramadan fasting' and 'Intermittent fasting' as keyword (publications between 2005 and 2018).

Discussion and Conclusion: Research-based molecular and clinical studies on Ramadan and other fasting methods agree that fasting has positive effects on human health. Fasting lead to better metabolic health by reducing inflammation and oxidative stress. Fasting therapy may contribute to the treatment and prevention of chronic diseases including cardiovascular diseases, cancer, diabetes, and neurological disorders. It can be said fasting would take place in physician recommendations as a complementary treatment method in the near future.
\end{abstract}

Keywords: fasting, Ramadan fasting, integrative medicine

\section{INTRODUCTION}

Fasting is abstinence from eating and drinking for a period of time willingly. The practice is known in ancient and modern cultures around the world. It is an important component of Islamic practice for healthy adults between dawn and sunset during the month of Ramadan. Fasting has also been used in nearly every religion in the world, including Judaism, Christianity, Islam and Buddhism as a means of treating the body and soul (1). However, intermittent fasting (IF) involves entirely or partially abstaining from eating for a set amount of time, before eating regularly again. It is a broad term that encompasses a variety of programs that manipulate the timing of eating occasions by utilizing shortterm fasts (2). Fasting began as a spiritual practice and recent research has verified its health benefits $(3,4)$. People abstain from eating a day to cleanse the body, for medical or spiritual reasons. The health effects of religious fasting have been documented at the Buddhist, Christian, and Muslim societies (1). Muslims fast during the holy month of Ramadan (The Holy Quran; Surah Al-Baqarah: Verses 183-185); the Prophet Muhammad also recommended fasting on some days of the week (Narrated by al-Tirmidhi, 745; Book 8, Hadith 64). In the US, therapeutic fasting with medical supervision, for treating or preventing illness, became popular in the $19^{\text {th }}$ century as part of the Natural Hygiene Movement (5). Later, the German physician Otto Buchinger, who systematically observed the effects of fasting on various diseases, was one of the first to develop the notion of therapeutic fasting (3). As discussed in the recent years $(4,6)$, can fasting be part of staying healthy? Fasting has in fact led to significant improvements in most health problems that have been investigated.

This review examines studies carried out on fasting practices, and it is reviewed lately conducted studies in regarding the impact of IF or Ramadan fasting on health. For the purpose, it was searched, MEDLINE/PubMed and Google Scholar databases by using the terms 'Fasting', 'Ramadan Fasting' and 'Intermittent Fasting' as keyword (in the publications between 2005 and 2018). In addition, some articles selected from the reference list of several articles on fasting were also examined.

\footnotetext{
Department of Biochemistry, Cerrahpasa Medical Faculty, Istanbul University, Istanbul, Turkey.
}

Correspondence: Ferah Armutcu

Private Esencan Hospital 19 Mayıs Bulvarı No:18 Esenyurt, Istanbul, Turkey.

Received: 19 Dec 2018, Accepted: 21 Feb 2019

E-mail:drferah@gmail.com

(C) 2019 by the authors; licensee Modestum Ltd., UK. This article is an open access article distributed under the terms and conditions of the Creative Commons Attribution License (http://creativecommons.org/licenses/by/4.0/). 
Table 1: Types of 'intermittent fasting' regimens that influence health outcomes, modified from ref. 6

\begin{tabular}{|c|c|}
\hline Type of fasting & Description \\
\hline Complete alternate-day fasting & $\begin{array}{l}\text { Involves alternating fasting days (energy-containing foods or beverages are not consumed) with normal eating } \\
\text { days }\end{array}$ \\
\hline Modified fasting regimens & $\begin{array}{l}\text { Allows consumption of } 20-25 \% \text { of energy needs on scheduled fasting days The basis for the popular } 5: 2 \text { diet, } \\
\text { which involves severe energy restriction for } 2 \text { non-consecutive days a week and ad libitum eating the other } 5 \text { days }\end{array}$ \\
\hline Time-restricted feeding & $\begin{array}{l}\text { Allows individuals to consume ad libitum energy intake within specific windows, which induces fasting periods on a } \\
\text { routine basis }\end{array}$ \\
\hline Religious fasting & There is a wide variety of fasting regimens are undertaken for religious or spiritual purposes \\
\hline Ramadan fasting & This type of fasting is undertaken from dawn to sunset (mean 15 hours) during the holy month of Ramadan* \\
\hline Other religious fasts & $\begin{array}{l}\text { Members of the Church of Jesus Christ of Latter-Day Saints routinely abstain from food and drink for extended } \\
\text { periods of time } \\
\text { Some Seventh-day Adventists consume their last of two daily meals in the afternoon, resulting in an extended } \\
\text { nighttime fasting interval }\end{array}$ \\
\hline
\end{tabular}

* Depending on the geographical location of those who are fasting during Ramadan, day fasting can vary from 11 to 19 hours

\section{IMPACT OF FASTING ON HUMAN HEALTH AND DISEASES}

Intermittent fasting is an eating pattern that involves the cycle between eating and fasting periods to improve body composition and overall health (2). As shown in Table 1, there are different intermittent fasting regimens that influence health outcomes. Although, data from related human studies are limited regarding the positive impacts of time-restricted feeding on weight or metabolic health, studies in rodents support the hypothesis that IF improve metabolic profiles and reduce the risks of obesity and obesity-related conditions, such as nonalcoholic fatty liver disease (NAFLD), and chronic diseases, such as diabetes and cancer (6). There are many studies of IF interventions in humans that assessed metabolic biomarkers of diabetes, cardiovascular (CV) disease, and cancer risk $(3,7)$. Tinsley and La Baunty $(7)$, reported that alternate-day fasting model is effective at reducing body weight, body fat, total cholesterol, and triglycerides in normalweight, overweight, and obese humans. Fasting is commonly associated with the month of Ramadan especially for muslim population. In recent years, numerous studies have also displayed that intermittent fasting can be good for health and, its one of the most popular diet trends worldwide (6). Additionally, it is claimed that both IF and Ramadan fasting to reduce oxidative damage and inflammation, optimize energy metabolism, and boost cellular protection $(8,9)$. For instance, the pattern of insulin resistance-mediating adipocytokines suggests potentially beneficial metabolic effects of Ramadan fasting (10). Fasting was shown to reduce body weight and have a positive effect on lipid profile and glucose levels (11). Feizollahzadeh et al. (12) reported high adiponectin levels, which may reduce metabolic stress induced by insulin resistance (IR) in seventy healthy men with predisposing factors such as type 2 Diabetes Mellitus (DM). Another study of young healthy individuals showed a positive impact on glucose homeostasis, adiponectin levels, and body mass index (BMI) (10). According to Celik et al. (13), Ramadan fasting has no negative effects on metabolic control variables such as insulin, C-peptide, $\mathrm{HbA1c}$, lipid profile, and weight in patients with type $2 \mathrm{DM}$. In a cros-sectional study, Yeoh et al. (14) have shown that Ramadan fasting practiced by patients with type 2 diabetes leads to a statistically and clinically significant reduction in $\mathrm{HbA} 1 \mathrm{c}$ levels of approximately 0.5 points, and that glycemic control is improved substantially during Ramadan fasting in 29 patients. In another study, normal subjects showed significant changes in various anthropometry parameters, but overweight and obese subjects showed no evident change (15). On the other hand, in an experimental rat study, it is found that IF significantly improves biochemical parameters associated with development of Diabetic nephropathy and changes the expression of Sir2 and p53 (16). There is increasing experimental evidence for positive effects of calorie restriction and IF in type 2 DM. Li et al. (17) claimed that prolonged fasting is practicable and might have useful clinical effects. Their study with 32 participants showed a significant decrease of blood pressure and non-significant ameliorations in $\mathrm{HbA} 1 \mathrm{c}$, insulin, and HOMA-index. Another study concluded there was promise for using IF to treat weight loss and reduce the risk of type $2 \mathrm{DM}$ in overweight and obese patients (18). Fasting therapy has a long tradition in Europe; in Germany, there are specialized fasting hospitals or clinical departments for complementary medicine (19). Results of an epidemiological study conducted among followers of the Church of the Latter Day Saints (29\% of whom undertake routine fasting) showed significantly lower weight and lower fasting glucose as well as lower prevalence of diabetes and coronary stenosis (20). Several studies have shown that Ramadan fasting reduces serum triglyceride, total cholesterol, LDL and VLDL cholesterol levels, but increases HDL cholesterol levels without a noticeable loss of weight $(21,22)$. Mathew et al.' study (23) showed significantly higher phosphatidylcholine concentrations in the fourth week of dawn-to-sunset fasting compared to the first week. In a study carried out with 83 patients, 42 of whom decided to fast and 41 of them decided not to fast, it is suggested that Ramadan fasting may be useful in treating NAFLD 


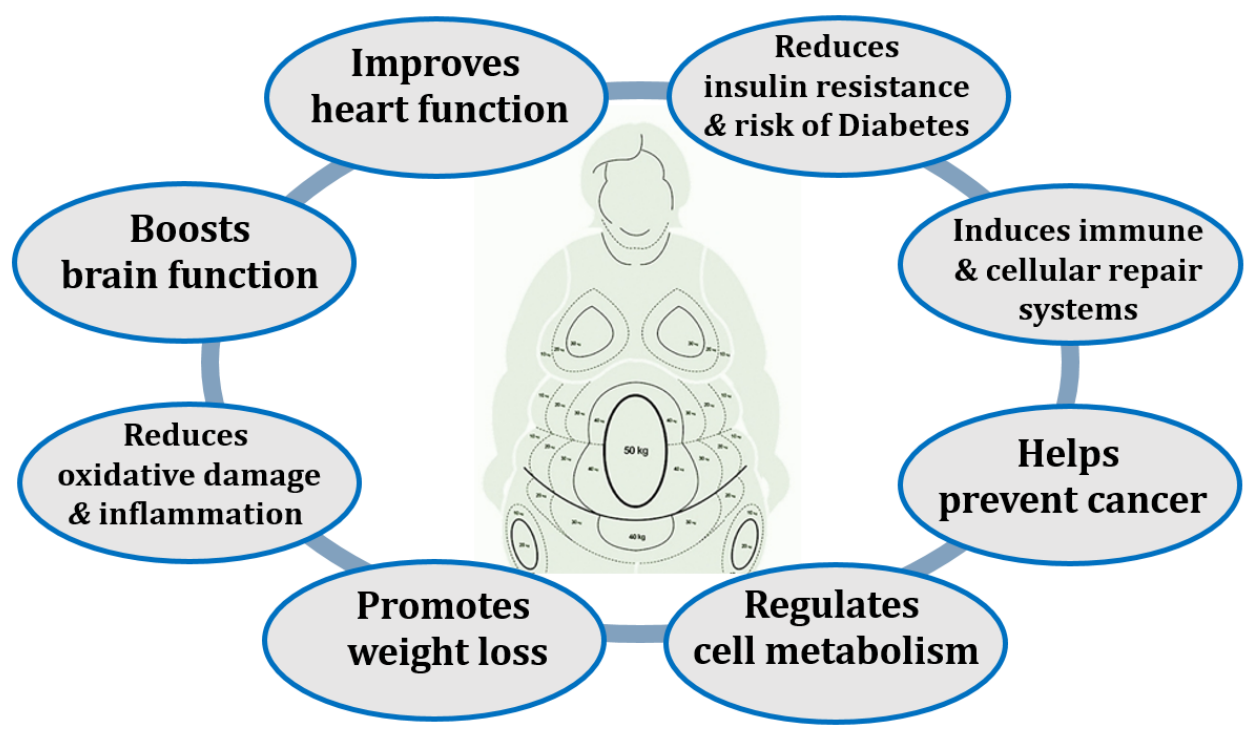

Figure 1: The positive effects of intermittent fasting about healthy life. Fasting regulates cellular and general metabolism by modifying the function of cells, genes and hormones in human body

because of its effect on anthropometric indicators, glucose, insulin, and inflammatory cytokines (24). Fasting may reduce systemic inflammation and pro-inflammatory cytokines, cell signaling molecules that make disease worse. Aksungar et al. (25) reported important changes in inflammatory markers, such as IL-6 and high-sensitivity C-reactive protein (hs(RP) in 40 healthy volunteers. In another cross-sectional study, Faris et al. reported that Ramadan fasting suppressed proinflammatory cytokine expression, decreased body fat and circulating levels of leukocytes in fifty (21 men, 29 women) healthy volunteers (26).

\section{IMPACT OF FASTING ON THE CELLULAR FUNCTIONS IN HEALTH AND DISEASES}

Intermittent fasting can lead to better metabolic health. In laboratory rats, IF has significant positive effects such as improving heart function and preventing cancer. It counteracts disease processes and improves functional effects in experimental models of a wide range of age-related disorders including CV diseases, cancer, diabetes, and neurological disorders such as Alzheimer's and Parkinson's disease $(4,9)$. Studies have shown it is effective for weight loss, alleviates multiple health indicators such as IR, and reduces risk factors for CV diseases. It can also improve the function of the immune system, and reduce the risk of chronic disease $(4,27)$. The useful effects is a result of activating adaptive cellularstress-response-signaling pathways that enhance DNA repair, mitochondrial health, and autophagy. Fasting induces autophagy, which encourages new growth of healthy cells and increases the body's ability to resist internal stressors (28). On the other hand, IF has a profound effect on gut barrier function in human, and reduces intestinal permeability (leaky gut). Li et al. (27) showed that fasting selectively stimulates beige fat development within white adipose tissue and dramatically reduces obesity and improves hepatic steatosis and IR. Fasting affects gut microbiota content, which leads to increases in lactate and acetate as well as selective upregulation of monocarboxylate transporter 1 expression in beige cells. Fasting helps the body repair and regenerate cells while boosting the immune system, still it also reduces oxidative stress (OS) and inflammation (29). Periodic fasting (PF) stimulates stem cell-based regeneration as well as long-lasting metabolic effects (4), In rodents, IF or PF protects against heart disease, cancer, diabetes, and neurodegeneration, while in humans it helps reduce obesity, hypertension, asthma, and rheumatoid arthritis (Figure 1), (29).

Ramadan fasting also has positive effects on inflammation as well as metabolic and anthropometric indices. Unalacak et al. (30) reported significant reductions in post-Ramadan blood pressure values, white blood cell counts, IL-2, IL-8, TNF- $\alpha$, triglyceride, and ALT levels. It has been suggested that Ramadan fasting may reduce CV risk factors. According to the results of a prospective observational study involving eighty two volunteers, after an average of 26 days of fasting, there was a significant improvement in ten-year coronary heart disease risk scores and other CV risk factors such as weight, $\mathrm{BMI}$, and waist circumference (31). In a more recent study, healthy 23 young volunteers were evaluated before Ramadan and two weeks into it. Ramadan fasting was associated with improvements in cardiometabolic risk factors such as circulating GGT, hs-CRP, and leukocyte expression of IL-1 $\alpha$ mRNA (32). Another recent study suggested that Ramadan fasting is safe and is not associated with significant changes in the symptoms of heart failure or an elevated risk of cardiac 
Table 2: The benefit effects of intermittent fasting on the body and brain. The nervous and endocrine system play a crucial role in this process as mediators of the adaptive responses of the major organ systems (The right-hand column contains related references)

\begin{tabular}{|c|c|c|}
\hline Brain & $\begin{array}{l}\text { Increased neurotrophic factors, enhanced cognitive function and network plasticity, increased stress } \\
\text { resistance, mitochondrial biogenesis, reduced oxidative stress, reduced inflammation, reduced seizures } \\
\text { and seizure-related brain damage }\end{array}$ & $1,2,6,21,29$ \\
\hline Heart & $\begin{array}{l}\text { Increased parasympathetic tone, reduced blood pressure, reduced resting heart rate, increased heart rate } \\
\text { variability, increased stress resistance }\end{array}$ & $\begin{array}{l}2,17,22,23,29,30, \\
31\end{array}$ \\
\hline Liver & Increased insulin sensitivity, glycogenolysis, ketogenesis, decreased IGF-1 levels & $6,11,17,23$ \\
\hline Muscles & Enhanced anabolism, increased insulin sensitivity, increased stress resistance & 6,25 \\
\hline Fat tissue & Lipolysis/ketogenesis, reduced inflammation, reduced leptin, increased adiponectin & $10,11,16,23$ \\
\hline Intestines & $\begin{array}{l}\text { Enhanced intestinal regeneration, reduced energy uptake, reduced inflammation, reduced cell } \\
\text { proliferation, increased stem cell number and activity }\end{array}$ & $6,16,30,37,38$ \\
\hline Circulating blood & Decreased insulin, leptin and IGF-1, increased ketones, adiponectin and ghrelin & $2,10,22,29,36$ \\
\hline $\begin{array}{l}\text { Cellular changes or } \\
\text { improvements }\end{array}$ & $\begin{array}{l}\text { Improved insulin sensitivity, cellular repair (autophagy), up-regulated mitochondrial biogenesis, reduced } \\
\text { oxidative damage and inflammation, changes in gene expression related to longevity and disease } \\
\text { protection }\end{array}$ & $\begin{array}{l}1,2,7,8,9,16,22 \\
25,28,29,37\end{array}$ \\
\hline $\begin{array}{l}\text { Common systemic } \\
\text { effects }\end{array}$ & $\begin{array}{l}\text { Stimulates brain function, improves heart function, increases fatty acid mobilization, improves glucose } \\
\text { tolerance, boosts the immune system, promotes weight loss, reduces risk of type } 2 \text { diabetes and obesity, } \\
\text { helps prevent cancer and promotes healthy aging }\end{array}$ & $\begin{array}{l}1,2,4,7,9,16,18 \\
27,29,38\end{array}$ \\
\hline
\end{tabular}

events (33). Some trials indicate that fasting has positive effects on body weight, glycemia, cardiometabolic risk, inflammation and OS markers (Table 2). In cardiac patients, Ramadan fasting have beneficial effects such as lipid profile improvement and alleviation of OS (34). It has been identified significant improvement in BMI, serum lipid profiles, and OS parameters by fasting. Asemi et al. (8) reported that Ramadan fasting in women with polycystic ovary syndrome for 4 weeks had beneficial effects on glutathione and nitric oxide levels. In those cross-sectional study on 27 patients with PCOS, it was not observed any significant effect of Ramadan fasting on glucose homeostasis parameters, lipid profile or total antioxidant capacity.

\section{POSITIVE EFFECTS OF FASTING ON THE NERVOUS AND IMMUNE SYSTEMS}

Although it is generally preferred to lose weight, other benefits of fasting can not be ignored, for example IF stimulates brain function helping to reduce the risk of neurological conditions. Fasting therapy may contribute to the treatment and prevention of chronic diseases including chronic degenerative and inflammatory diseases (29). Fasting followed by a vegetarian diet led to improvements in rheumatoid arthritis in randomized controlled trials. Other potential health benefits are enhanced production of neurotrophic factors, decreased mitochondrial OS, general decline of signals associated with aging, and higher rates of autophagy $(3,29)$. There is increasing research that ties fasting to physical and mental health. For example, participated seventy-three healthy volunteers, in a recent study demonstrated that fasting in the month of Ramadan reduces stress, anxiety, and depression (35). In another study, no major effect was found on body composition, glucose homeostasis, or cognitive function (9). Neither memory, executive functions, nor attention were affected by Ramadan fasting. It has also been suggested that IF induces adaptive responses in the brain and periphery that can suppress inflammation and preserve cognitive function, in an animal model of systemic bacterial infection (36). As shown in Table 2, IF modifies brain neurochemistry and neuronal network activity in ways that optimize brain function and peripheral energy metabolism (29).

Fasting has been practiced for millennia, but only recently have studies begun to shed light on its role in adaptive cellular responses that reduce inflammation and oxidative damage, optimize energy metabolism, and increase cellular protection. Levels of OS and inflammation are reduced throughout the body and brain in response to IF. This may lead to positive changes that could improve learning and protect against diseases like Alzheimer's. Fasting increased circulating blood ketones, which play a vital role in shifting the structure of neural synapses to promote learning and overall brain health. Intermittent fasting has the potential to prevent and reverse chronic illnesses such as obesity, hypertension, and asthma (29). It even shows promise for improving response to autoimmune diseases such as rheumatoid arthritis and multiple sclerosis (37). Intermittent fasting enhances insulin sensitivity of muscle and liver cells and reduces insulin growth factor-1 (IGF-1) production. Animals given a diet that includes fasting lost weight and had lower levels of glucose, triacylglycerols, and IGF-1 (6). Fasting significantly reduces leptin, a type of pro-inflammatory cytokine that is elevated in patients with rheumatoid arthritis, type 1 diabetes, autoimmune hepatitis, and multiple sclerosis $(29,37)$. By protecting cells from DNA damage, suppressing cell growth, and enhancing apoptosis of damaged 
cells, fasting may retard or prevent the formation and growth of cancers (29). According to an experimental study, fasting promotes regeneration and reduces autoimmunity. Choi et al. (37) have suggested that a fasting diet is effective in ameliorating demyelination and symptoms in a murine experimental autoimmune encephalomyelitis model. Recently, Mihaylova et al. (38) showed that short-term fasting promotes intestinal stem and progenitor cell function in young and old mice by inducing robust fatty acid oxidation. They reported that fasting has many effects on the intestines, which include promoting regeneration as well as potential benefits against disease, infection, and cancer. According to Patterson et al. (6), intermittent fasting regimens are assumed to influence metabolic regulation via effects on circadian biology, the gut microbiome, and modifiable lifestyle behaviors. Briefly, research-based molecular and clinical studies on Ramadan and other fasting methods agree that fasting has positive effects on human health (Figure 1).

\section{WHAT ARE THE UNDESIRABLE EFFECTS OF FASTING?}

Meanwhile, it is known there are various health risks associated with both Ramadan and IF including dehydration, heartburn, high stress levels and sleep disorder $(5,39)$. Also, there are some potential complications or risks associated with fasting in patients with diabetes including hypoglycemia, hyperglycemia, diabetic ketoacidosis, dehydration and thrombosis (40). Notably, women who are pregnant or have gestational diabetes, as well as breastfeeding women and elderly people should be advised not to fast during the month of Ramadan. In this regards, patient education, regular glucose monitoring, and adjustment of treatment regimens are constantly updated to minimize adverse effects in patients with diabetes who want to fast (41). Some studies have evaluated mood or other behavioral side effects in response to the fasting regime; a small number (in general $<15 \%$ ) of participants reported negative side effects such as feeling cold, hungry, low energy, or irritable $(6,21,39)$. According to a systematic review study, the literature does not support the association of Ramadan fasting with any change in the incidence of cardiovascular disease (42). On the other hand, there is controversy between studies about the risk of dehydration in Ramadan in developing renal stones (43). The results of 237 patients (retrospective cross-sectional study) showed that fasting in Ramadan does not increase the risk for developing urinary tract stones compared to non-fasting months (44). Ultimately, much remains to be learned about fasting of religious or intermittent; however, the positive findings to date serve to encourage promising our hypothesis in this paper.

\section{CONCLUSION}

Fasting practices have clear health benefits. Recent studies have shed light on the role of fasting in adaptive cellular responses that reduce oxidative damage and inflammation, optimize energy metabolism, and bolster cellular protection. While chronic fasting extends longevity in part by reprogramming metabolic and stress resistance pathways in eukaryotes, rodents have been observed to be protected by IF or PF against diabetes, heart disease, cancer and neurodegeneration. In humans, it helps to reduce obesity, CV disease, metabolic syndrome, NAFLD, and inflammatory diseases such as asthma and rheumatoid arthritis. In this brief review, we concluded that fasting can be part of a healthy potential lifestyle to promote optimal health and reduces the risk of many chronic illnesses, based on available evidence from animal and human studies. In healthy adults, there are no adverse effects of Ramadan fasting on the body, brain, or in endocrine and cognitive functions. We also conclude that fasting is a healthy and non-pharmacological means of minimizing risk factors while improving health. Although Ramadan fasting is safe for all healthy individuals, those with illnesses such as diabetes, coronary artery, and renal diseases should consult their physicians. In the light of this data, we think that fasting may have a place as an alternative or integrative treatment option in doctors' recommendations in the near future.

\section{REFERENCES}

1. Persynaki A, Karras S, Pichard C. Unraveling the metabolic health benefits of fasting related to religious beliefs: A narrative review. Nutrition. 2017;35:14-20. https://doi.org/10.1016/j.nut.2016.10.005

2. Patterson RE, Laughlin GA, LaCroix AZ, et. al. Intermittent fasting and human metabolic health. J Acad Nutr Diet. 2015;115:1203-1212. https://doi.org/10.1016/j.jand.2015.02.018

3. Michalsen A, Li C. Fasting therapy for treating and preventing disease - current state of evidence. Forsch Komplementmed. 2013;20:444-453. https://doi.org/10.1159/000357765

4. Mattson MP, Longo VD, Harvie M. Impact of intermittent fasting on health and disease processes. Ageing Res Rev. 2017;39:46-58. https://doi.org/10.1016/j.arr.2016.10.005 
5. Boschmann M, Michalsen A. Fasting therapy - old and new perspectives. Forsch Komplementmed. 2013;20:410411. https://doi.org/10.1159/000357828

6. Patterson RE, Sears DD. Metabolic effects of intermittent fasting. Annu Rev Nutr. 2017;37:371-393. https://doi.org/10.1146/annurev-nutr-071816-064634

7. Tinsley GM, La Bounty PM. Effects of intermittent fasting on body composition and clinical health markers in humans. Nutr Rev. 2015;73:661-674. https://doi.org/10.1093/nutrit/nuv041

8. Asemi Z, Samimi M, Taghizadeh M, Esmaillzadeh A. Effects of Ramadan fasting on glucose homeostasis, lipid profiles, Inflammation and oxidative stress in women with polycystic ovary syndrome in Kashan, Iran. Arch Iran Med. 2015;18:806-810. https://doi.org/0151812/AlM.003

9. Harder-Lauridsen NM, Rosenberg A, Benatti FB, et al. Ramadan model of intermittent fasting for $28 \mathrm{~d}$ had no major effect on body composition, glucose metabolism, or cognitive functions in healthy lean men. Nutrition 2017;37:92-103. https://doi.org/10.1016/j.nut.2016.12.015

10. Gnanou JV, Caszo BA, Khalil KM, et al. Effects of Ramadan fasting on glucose homeostasis and adiponectin levels in healthy adult males. J Diabetes Metab Disord. 2015;14:55. https://doi.org/10.1186/s40200-015-0183-9

11. Kiyani MM, Memon AR, Amjad Ml, et al. Study of human biochemical parameters during and after Ramadan. J Relig Health. 2017;56:55-62. https://doi.org/10.1007/s10943-015-0084-8

12. Feizollahzadeh $\mathrm{S}$, Rasuli J, Kheirouri $\mathrm{S}$, Alizadeh $\mathrm{M}$. Augmented plasma adiponectin after prolonged fasting during ramadan in men. Health Promot Perspect. 2014;4:77-81. https://doi.org/10.5681/hpp.2014.010

13. Celik S, Pinar R, Uzum AK, Salman S. Effects of Ramadan fasting on daily life and metabolic condition in patients with type 2 Diabetes. Turkiye Klinikleri J Med Sci. 2013;33:1266-1273. https://doi.org/10.5336/medsci.201233028

14. Yeoh EC, Zainudin SB, Loh WN, Chua CL, Fun S, et al. Fasting during Ramadan and associated changes in glycaemia, caloric intake and body composition with gender differences in Singapore. Ann Acad Med Singap. 2015;44:202-206. Retrieved from https://www.ncbi.nlm.nih.gov/pubmed/26292948

15. Rohin MA, Rozano N, Abd Hadi N, Mat Nor MN, Abdullah S, Dandinasivara Venkateshaiah M. Anthropometry and body composition status during ramadan among higher institution learning centre staffs with different body weight status. Scientific World Journal. 2013;2013:308041. https://doi.org/10.1155/2013/308041

16. Tikoo K, Tripathi DN, Kabra DG, et al. Intermittent fasting prevents the progression of type I diabetic nephropathy in rats and changes the expression of Sir2 and p53. FEBS Lett. 2007;581:1071-1078. https://doi.org/10.1016/j.febslet.2007.02.006

17. Li C, Sadraie B, Steckhan N, et al. Effects of A One-week Fasting Therapy in Patients with Type-2 Diabetes Mellitus and Metabolic Syndrome - A Randomized Controlled Explorative Study. J Exp Clin Endocrinol Diabetes. 2017;125:618-624. https://doi.org/10.1055/s-0043-101700

18. Barnosky AR, Hoddy KK, Unterman TG, Varady KA. Intermittent fasting vs daily calorie restriction for type 2 diabetes prevention: a review of human findings. Transl Res. 2014;164:302-311. https://doi.org/10.1016/j.trsl.2014.05.013

19. Lauche $R$, Wardle J, Ostermann $T$, et al. Characteristics of fasting users among internal medicine patients in Germany. Adv Integr Med. 2018;5:29-34. https://doi.org/10.1016/j.aimed.2017.12.005

20. Horne BD, May HT, Anderson JL, et al. Usefulness of routine periodic fasting to lower risk of coronary artery disease in patients undergoing coronary angiography. Am J Cardiol. 2008;102:814-819. https://doi.org/10.1016/j.amjcard.2008.05.021

21. Meo SA, Hassan A. Physiological changes during fasting in Ramadan. J Pak Med Assoc. 2015;65(Suppl 1):6-14.

22. Mindikoglu AL, Opekun AR, Gagan SK, Devaraj S. Impact of Time-Restricted Feeding and Dawn-to-Sunset Fasting on Circadian Rhythm, Obesity, Metabolic Syndrome, and Nonalcoholic Fatty Liver Disease. Gastroenterol Res Pract. 2017;2017:3932491. https://doi.org/10.1155/2017/3932491

23. Mathew S, Krug S, Skurk T, et al. Metabolomics of Ramadan fasting: an opportunity for the controlled study of physiological responses to food intake. J Transl Med. 2014;12:161. https://doi.org/10.1186/1479-5876-12-161

24. Aliasghari F, Izadi A, Gargari BP, Ebrahimi S. The Effects of Ramadan Fasting on Body Composition, Blood Pressure, Glucose Metabolism, and Markers of Inflammation in NAFLD Patients: An Observational Trial. J Am Coll Nutr. 2017;36:640-645. https://doi.org/10.1080/07315724.2017.1339644

25. Aksungar FB, Topkaya AE, Akyildiz M. Interleukin-6, C-reactive protein and biochemical parameters during prolonged intermittent fasting. Ann Nutr Metab. 2007;51:88-95. https://doi.org/10.1159/000100954 
26. Faris MA, Kacimi S, Al-Kurd RA, et al. Intermittent fasting during Ramadan attenuates proinflammatory cytokines and immune cells in healthy subjects. Nutr Res. 2012;32:947-955. https://doi.org/10.1016/j.nutres.2012.06.021

27. Li G, Xie C, Lu S, et al. Intermittent fasting promotes white adipose browning and decreases obesity by shaping the gut microbiota. Cell Metab. 2017;26:672-685. https://doi.org/10.1016/j.cmet.2017.08.019

28. Liu H, Javaheri A, Godar RJ, et al. Intermittent fasting preserves beta-cell mass in obesity-induced diabetes via the autophagy-lysosome pathway. Autophagy. 2017;13:1952-1968. https://doi.org/10.1080/15548627.2017. 1368596

29. Longo VD, Mattson MP. Fasting; molecular mechanisms and clinical applications. Cell Metab. 2014;19:181-192. https://doi.org/10.1016/j.cmet.2013.12.008

30. Unalacak M, Kara IH, Baltaci D, Erdem O, Bucaktepe PG. Effects of Ramadan fasting on biochemical and hematological parameters and cytokines in healthy and obese individuals. Metab Syndr Relat Disord. 2011;9:157161. https://doi.org/10.1089/met.2010.0084

31. Nematy $M$, Alinezhad-Namaghi $M$, Rashed MM, et al. Effects of Ramadan fasting on cardiovascular risk factors: a prospective observational study. Nutr J. 2012;11: 69. https://doi.org/10.1186/1475-2891-11-69

32. Ajabnoor GM, Bahijri S, Shaik NA, et al. Ramadan fasting in Saudi Arabia is associated with altered expression of CLOCK, DUSP and IL-1alpha genes, as well as changes in cardiometabolic risk factors. PLoS One. 2017;12:e0174342. https://doi.org/10.1371/journal.pone.0174342

33. Abazid RM, Khalaf HH, Sakr HI, et al. Effects of Ramadan fasting on the symptoms of chronic heart failure. Saudi Med J. 2018;39:395-400. https://doi.org/10.15537/smj.2018.4.22011

34. Adawi M, Watad A, Brown S, et al. Ramadan Fasting Exerts Immunomodulatory Effects: Insights from a Systematic Review. Front Immunol. 2017;8:1144. https://doi.org/10.3389/fimmu. 2017.01144

35. Erdem $O$. The investigation of the effects of Ramadan fasting on the mood state of healthy volunteer persons. Fam Pract Palliat Care. 2018;3:1-6. https://doi.org/10.22391/fppc.398323

36. Vasconcelos AR, Yshii LM, Viel TA, et al. Intermittent fasting attenuates lipopolysaccharide-induced neuroinflammation and memory impairment. J Neuroinflammation. 2014;11:85. https://doi.org/10.1186/17422094-11-85

37. Choi IY, Piccio L, Childress P, et al. A Diet Mimicking Fasting Promotes Regeneration and Reduces Autoimmunity and Multiple Sclerosis Symptoms. Cell Rep. 2016;15:2136-2146. https://doi.org/10.1016/j.celrep.2016.05.009

38. Mihaylova MM, Cheng CW, Cao AQ, et al. Fasting Activates Fatty Acid Oxidation to Enhance Intestinal Stem Cell Function during Homeostasis and Aging. Cell Stem Cell. 2018;22:769-778. https://doi.org/10.1016/j.stem.2018. 04.001

39. Watkins E, Serpell L. The Psychological Effects of Short-Term Fasting in Healthy Women. Front Nutr. 2016;3:27. https://doi.org/10.3389/fnut.2016.00027

40. Al-Arouj M, Bouguerra R, Buse J et al. Recommendations for management of diabetes during Ramadan. Diabetes Care 2005;28:2305-2311. https://doi.org/10.2337/diacare.28.9.2305

41. Mahmoud Ibrahim, Megahed Abu Al Magd, Firas A Annabi, et al. Recommendations for management of diabetes during Ramadan: update 2015. BMJ Open Diabetes Res Care. 2015;3(1):e000108. https://doi.org/10.1136/bmjdrc-2015-000108

42. Mazidi M, Rezaie P, Chaudhri O, Karimi E, Nematy M. The effect of Ramadan fasting on cardiometabolic risk factors and anthropometrics parameters: A systematic review. Pak J Med Sci. 2015;31:1250-1255. https://doi.org/10.12669/pjms.315.7649

43. Emami-Naini A, Roomizadeh $P$, Baradaran A, Abedini A, Abtahi M. Ramadan fasting and patients with renal diseases: A mini review of the literature. J Res Med Sci. 2013;18:711-716. Retrieved from https://www.ncbi.nlm.nih.gov/pmc/articles/PMC3872613/

44. Al Mahayni AO, Alkhateeb SS, Abusaq IH, et al. Does fasting in Ramadan increase the risk of developing urinary stones? Saudi Med J. 2018;39:481-486. https://doi.org/10.15537/smj.2018.5.22160

$\diamond \diamond \diamond \diamond \diamond \diamond \diamond$

http://www.ejgm.co.uk 